\title{
STATE-OF-THE-ART ANALYSIS FOR THE FRACTURE ENERGY OF CONCRETE: REVISITED
}

\author{
MYUNG K. LEE ${ }^{\dagger}$, SUNG W. YOO ${ }^{\dagger \dagger}$ AND BYUNG H. OH ${ }^{\dagger \dagger \dagger}$ \\ ${ }^{\dagger}$ Jeonju University \\ Jeonju-si, Jeonbuk, Korea \\ e-mail: concrete@jj.ac.kr \\ ${ }^{\dagger \dagger}$ Woosuk University \\ Jinchon, Chungbuk, Korea \\ e-mail: imysw@woosuk.ac.kr \\ ${ }^{\dagger \dagger}$ Seoul National University \\ Seoul, Korea \\ e-mail: bhohcon@snu.ac.kr
}

Key words: Fracture Energy, Fracture Process Zone, Fracture Volume, FPZ size, Size Effect.

\begin{abstract}
Fracture mechanics of concrete play an important role in describing fracture process in concrete members. Fracture energy is a key parameter in employing the fracture mechanics in concrete structures. To determine the fracture energy of concrete, the formation and progress of fracture process zone in front of crack tip have to be identified appropriately. Therefore, the development of fracture process zone was modeled in this study based on the concept of fractured volume. The fractured volume was defined in terms of the length and width of the fracture process zone. The length of fracture process zone was modeled based on the data of cohesive stress analyses. The continuous change of length and width of fracture process zone was modeled as a crack propagates along the ligament. The present model may allow more realistic evaluation and interpretation for the fracture energy of concrete in that it gives the fracture energy per unit volume of concrete in addition to the fracture energy per unit area of concrete. However, further study is necessary to clarify the patterns of change of FPZ size along the ligament according to various member sizes because the decreasing pattern of FPZ size according to crack-to-depth ratio may be different for different sizes of members. This task must be also implemented for the variation of width of FPZ for different member sizes. This will enable us to describe reasonably the fracture energy of concrete per unit volume for any sizes of members.
\end{abstract}

\section{INTRODUCTION}

Fracture energy of concrete is an essential parameter to characterize the fracture behaviour of concrete. It is a necessary parameter to identify the crack propagation in concrete $[1,2]$. In this regard, many researchers have studied experimentally and theoretically on the fracture energy of concrete during last several decades[1-12].

Many researchers reported that the fracture energy of concrete depends on the size, shape, and compositions of specimens. The mixture compositions may surely affect the fracture energy of concrete because different mixtures 
may give different microstructures and thus different strengths and ductility.

On the other hand, there are still controversial aspects for the size dependency of fracture energy. This thought comes from the fact that fracture energy is defined as the energy required to open unit area of crack surface and thus it may be a material property that does not depend on size of structure. However, in reality, many experimental results reveal that there exists great size dependency in fracture energy of concrete for same material mixtures[3-12].

In this study, therefore, thorough review of existing studies on fracture energy of concrete has been done. The formation and progress of fracture process zone in front of crack tip were then analyzed from the data. The volume of fracture process zone was defined in this study and identified from the data of damage progress at the crack tip.

\section{REVIEW OF TEST METHODS AND TEST RESULTS ON FRACTURE ENERGY OF CONCRETE}

Many studies have been done to explore the fracture properties of concrete. Among others, the fracture energy of concrete has received most attention because it is a main important parameter in the fracture analysis of concrete structures. The fracture energy of concrete may be obtained from the work of fracture method and the size effect method. The main feature of these methods is summarized as follows..

\subsection{Work of fracture method}

The fracture energy of concrete may be determined based on the RILEM recommendation[13]. This recommendation specifies the method of determining fracture energy from notched beams[13]. The fracture energy may be calculated simply from a loaddisplacement curve obtained from stable three point bend test of a notched beam as follows.

$$
G_{f}(a)=\frac{\mathrm{W}_{1}+\mathrm{mg} \delta_{0}}{(\mathrm{D}-\mathrm{a}) \mathrm{b}}
$$

where $G_{f}(a)=$ fracture energy of concrete corresponding to the initial crack(notch) length $a, \mathrm{D}=$ beam depth, $\mathrm{b}=$ beam width (thickness), $\mathrm{W}_{1}=\int \mathrm{P} d \delta, \mathrm{P}=$ applied load at the center point of beam, $\delta=$ load point displacement, $m$ is the total mass of the specimen, $g$ is gravity, and $\delta_{0}$ is the end deflection at $\mathrm{P}=0$, respectively.

The above equation(Eq. 1) implies that the fracture energy per unit area of crack extension equals the total work of fracture divided by the projected ligament area. Therefore, this may be called as the work of fracture method(WFM). This WFM may also be applied to the case of wedge splitting tests.

\subsection{Size effect method}

Size effect of concrete members has been basically introduced to delineate the effect of size on the nominal failure strength of the members. In this regard, Bazant proposed the size effect law as follows[14, 15 ].

$$
\sigma_{N}=\frac{\mathrm{Bf}^{\prime}{ }_{\mathrm{t}}}{\sqrt{1+\mathrm{D} / \mathrm{D}_{0}}}
$$

where $\sigma_{N}=$ nominal failure stress, $\mathrm{f}_{\mathrm{t}}=$ tensile strength, $\mathrm{D}=$ beam size, $\mathrm{B}$ and $\mathrm{D}_{0}=$ empirical coefficients to be identified by optimum fitting of measured $\sigma_{N}$ values covering a broad enough size range, respectively.

The fracture energy $G_{f}$ of concrete may be obtained from the size effect law of Eq. (2) as follows $[14,15]$.

$$
G_{\mathrm{f}}=\frac{\left(\mathrm{Bf}_{\mathrm{t}}^{\prime}\right)^{2} \mathrm{D}_{0} \mathrm{~g}\left(\alpha_{0}\right)}{\mathrm{E}^{\prime}}=\frac{\mathrm{g}\left(\alpha_{0}\right)}{\mathrm{E}^{\prime} \mathrm{A}}
$$

where $\alpha_{0}=a_{0} / D, g\left(\alpha_{0}\right)=k^{2}(\alpha)=$ dimensionless energy release rate function of linear elastic fracture mechanics, $\mathrm{E}^{\prime}=\mathrm{E}=$ Young's modulus for plane stress and $E^{\prime}=E /(1-v)$ for plane strain, and $v=$ Poisson's ratio, respectively. It is noted that $G_{f}$ here represents the initial fracture energy which is obtained from the area under the initial tangent of the cohesive softening stress-separation law.

\subsection{Review of test data on fracture energy}

Many researchers reported their test results on fracture energy of concrete using tree-point bend tests or wedge-splitting tests, by 
employing the above-mentioned work of fracture method or size effect method. They reported that there exists considerable sizedependency in fracture energy of concrete, meaning that fracture energy increases with an increase of specimen size[3-12]. They also pointed out that fracture energy decreases with an increase of initial notch length for samesized specimens. Wittmann et al.[4] presumed that the tail part of cohesive stress-separation law may contribute to this size effect and the final separation displacement at zero cohesive stress may increase with specimen size. Kwon et al.[7] also commented that the tail part of the softening stress-separation curve, which was obtained by inverse analysis of fracture test data, becomes longer with increasing specimen size.

Guo and Gilbert[6] mentioned that in reality the size of the specimen does affect the measurement of fracture energy, even when the size of the specimen is such that the fracture process zone develops fully. They argued that this may be due to the local plastic deformation in the area around the loading point which is particularly significant in larger specimens. Guinea et al.[8] and Planas et al.[9] reported that the test preparation, support condition, and bulk energy dissipation may influence the measurement of fracture energy, but these contributions are not enough to explain the size effect of fracture energy. Elices et al.[10] further commented that the energy dissipated at the very end of the test should be carefully considered in order to obtain realistic fracture energy values.

$\mathrm{Hu}$ and Wittmann[11, 12] introduced the local fracture energy concept along the crack line and this local fracture energy is assumed to vary with the width of the fracture process zone. Abdalla et al.[16, 17] argued that the size-independent specific fracture energy $\left(G_{F}\right)$ may be obtained from measured fracture energy values that vary with the size of the specimen and notch-to-depth ratio. Cifuentes et al.[18] conducted three-point bend tests to determine the size-independent specific fracture energy values of concrete by employing both the local fracture energy concept and the P- $\delta$ curve adjusting method [10], and shown that both methods give almost similar results.

\section{FORMATION AND PROGRESS OF FRACTURE PROCESS ZONE AT CRACK FRONT}

It is well-known that microcracking and thus damage zone occurs in front of crack tip in concrete with loading. This microcracking zone is called fracture process zone(FPZ). Much attention has been paid to identify the characteristics of FPZ because it plays a prime role in the fracture behavior and fracture analysis of concrete structures.

\subsection{Development of fracture process zone(FPZ)}

Petersson[2] investigated the development of FPZ in concrete by employing fictitious crack model. Figure 1 summarizes the various stages of fracture analysis for the three point bend test beams based on the fictitious crack model[2]. The beam height(depth) and beam length are $200 \mathrm{~mm}$ and $800 \mathrm{~mm}$, respectively.

The stage 1 of Figure 1 shows the stress distribution along the ligament at the load point 1 in Figure 1(e). It can be seen that the fracture (microcracking) zone just started at this stage. The stage 2 here exhibits the stress distribution along the ligament at the maximum load point [the load point 2 in Figure 1(e)]. At this stage the fracture process zone(FPZ) has progressed up to about $50 \mathrm{~mm}$ from the initial notch tip, but the FPZ was not fully-developed yet. The stage 3[Figure 1(c)] depicts the fully-developed fracture process zone and stress distribution along the ligament. The length of the first fully-developed FPZ was found to be about $80 \mathrm{~mm}$ from the initial notch tip.

The stage 4[Figure 1(d)] shows that a certain real crack of about $30 \mathrm{~mm}$ has been progressed in front of the initial notch tip at the load point 4 . It is interesting to see that the length of fully-developed FPZ at this stage 4 became about $68 \mathrm{~mm}$ which is smaller than the first (previously) developed full FPZ length of $80 \mathrm{~mm}$ in Figure 1(c). This means that the 
length of fully-developed FPZ, $l_{F}$, becomes smaller as the crack propagates further to the opposite side.

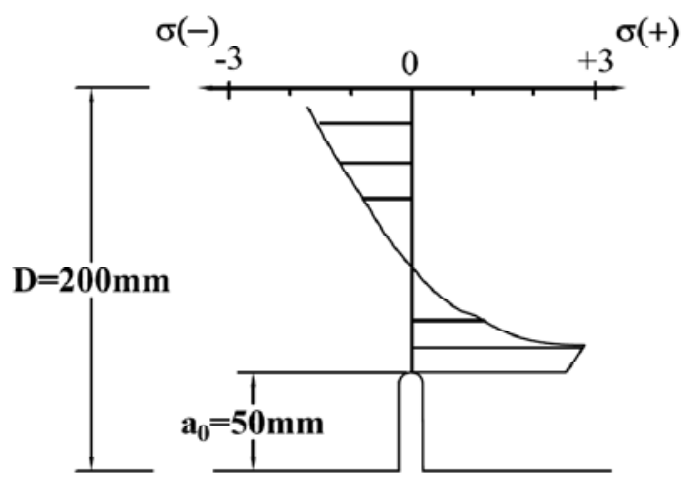

(a) stage (1)

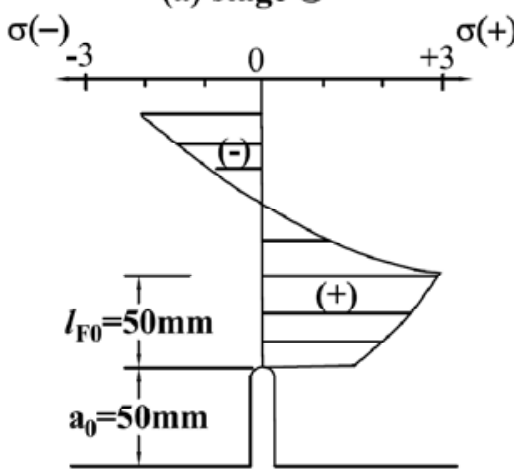

(b) stage (2)

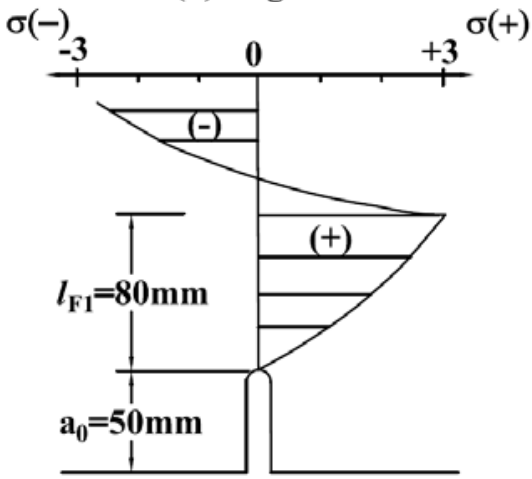

(c) stage (3)

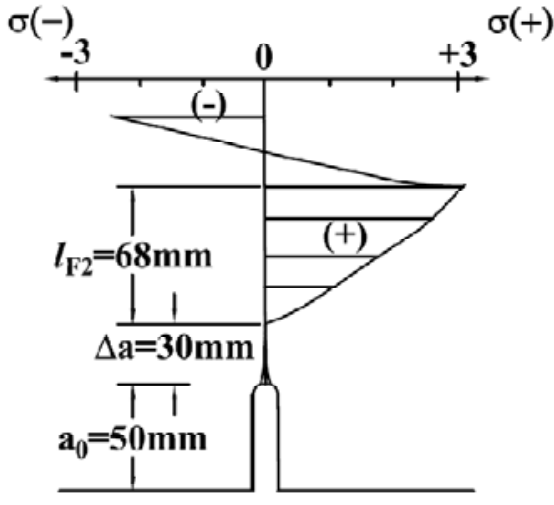

(d) stage (4)

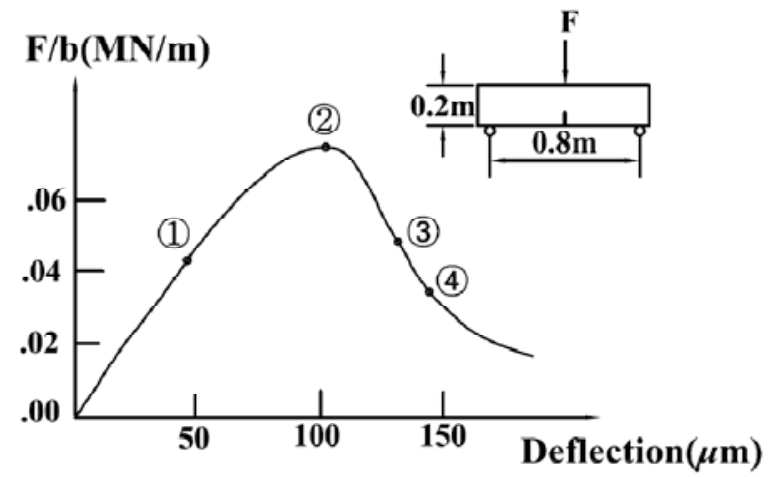

(e) Load-deflection curve

Figure 1: Movement of stress distribution and fracture process zone according to loading in front of crack in three point bending. [The stages 1,2,3, and 4 represent the corresponding load points in load-deflection curve of Figure 1(e)][2].

Figure 2 shows the reanalysis results from Petersson's data[2] on fully-developed FPZ lengths for various initial notch-to-beam depth ratios of three point bend beams. The depth and length of the beam are $200 \mathrm{~mm}$ and $800 \mathrm{~mm}$, respectively. The results indicate that the full FPZ length without initial crack $\left(a_{0} / D=0\right)$ is about $98 \mathrm{~mm}$ and the full FPZ lengths for $a_{0} / D=0.2,0.4$, and 0.6 are about $84 \mathrm{~mm}, 68 \mathrm{~mm}$, and $52 \mathrm{~mm}$, respectively. Here, the full FPZ length is defined as the length from the point of tensile strength to the point of zero cohesive stress.

This variation of fully-developed FPZ length $\left(l_{F}\right)$ according to initial crack to beam depth ratios is graphically shown in Figure 3 to clearly see the distinct decrease of full FPZ length with increasing crack length to depth ratio. Figure 3 indicates that the fullydeveloped FPZ length linearly decreases with an increase of the crack length-to-beam depth ratio. In another word, the full FPZ length decreases with a decrease of ligament length. The correlation coefficient was 0.999 which indicates almost perfect linear relation as shown in Figure 3.

In summary, Figure 2 and Figure 3 indicate that the fully-developed FPZ length is not constant for the same beam, but varies according to crack length-to-beam depth ratio( or ligament ratio). 


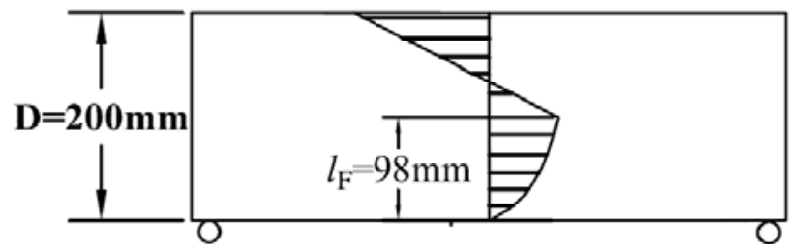

(a) Case $1: \mathrm{a}_{0} / \mathrm{D}=\mathbf{0}$

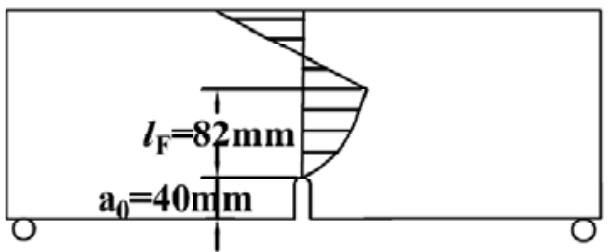

(b) Case $2: \mathrm{a}_{0} / \mathrm{D}=\mathbf{0 . 2}$

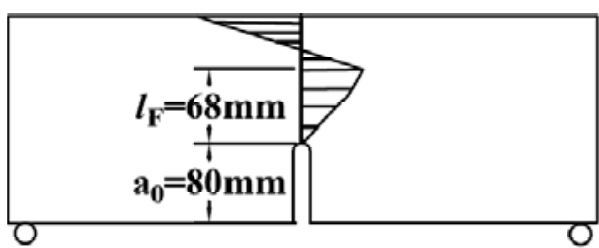

(c) Case $3: a_{0} / D=0.4$

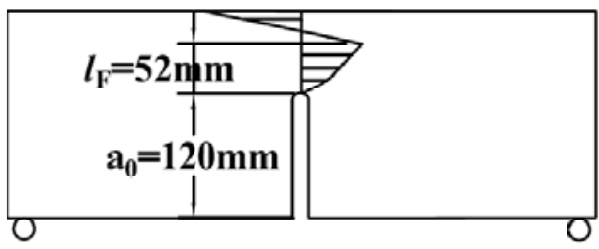

(d) Case $4: a_{0} / D=0.6$

Figure 2: Decrease of fracture process zone length with increasing crack length (Beam depth $\mathrm{D}=200 \mathrm{~mm}$, Beam length $=800 \mathrm{~mm}$ ).

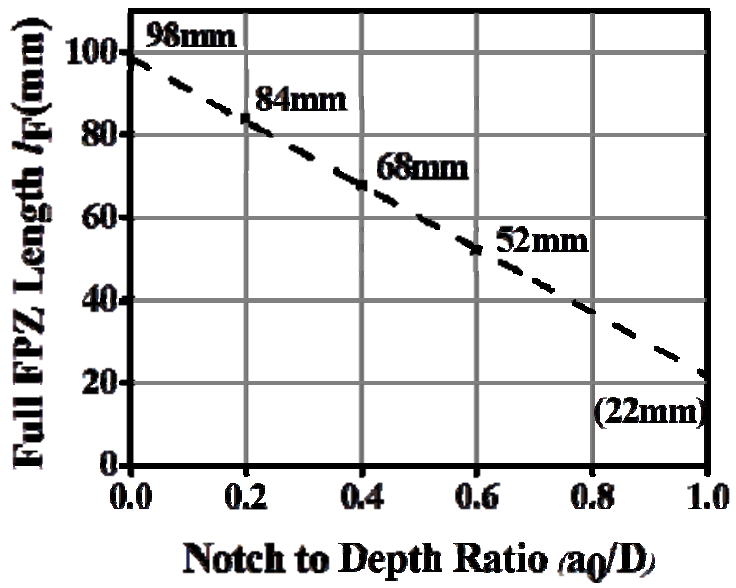

Figure 3: Variation of fully-deveolped FPZ length according to initial crack-to-depth $\operatorname{ratio}(\mathrm{D}=200 \mathrm{~mm})$.

Figure 4 depicts the relative ratios of full FPZ length according to initial crack length-tobeam depth ratio for the same beams. Figure 4 exhibits again a decrease of fully-developed
FPZ length with increasing crack length. The reason may be due to the fact that the available space for the FPZ to develop fully becomes smaller as crack propagates and also the ligament must accommodate the stress gradient to maintain equilibrium.

Therefore, the development of FPZ is affected by crack length-ligament ratio. Gopalaratnam and Ye[19] commented from their analysis that on further crack growth the process zone size diminished gradually due to a combination of edge effects and compressive stress fields that restrain its free growth.

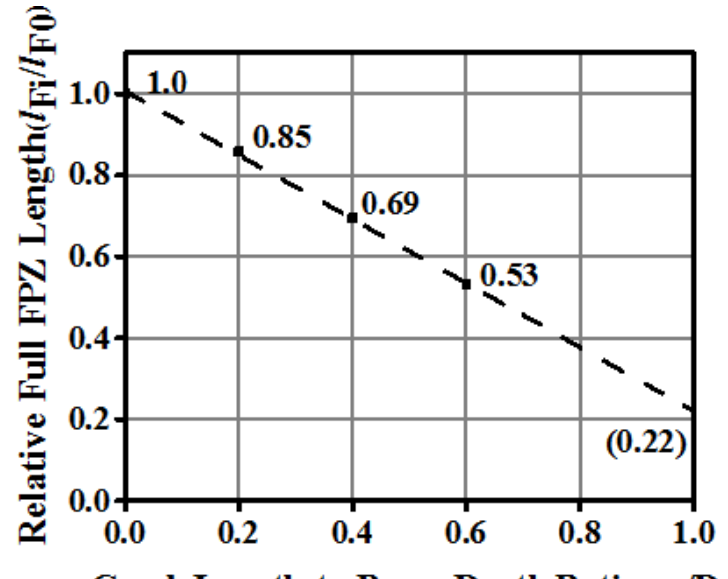

Crack Length-to-Beam Depth Ratio $\left(\mathbf{a}_{0} / \mathbf{D}\right)$

Figure 4: Relative ratios of fully-deveolped FPZ length, according to initial crack-to-beam depth ratio $(\mathrm{D}=200 \mathrm{~mm})$.

The relative ratio of fully-developed FPZ length to the first fully-developed FPZ length at zero initial crack may be expressed from Figure 4 for $\mathrm{D}=200 \mathrm{~mm}$ as follows.

$$
\frac{\mathrm{l}_{\mathrm{Fi}}}{\mathrm{l}_{\mathrm{F} 0}}=1--0.785\left(\frac{\mathrm{a}}{\mathrm{D}}\right)
$$

where $1_{\mathrm{Fi}}=$ full FPZ length at $i$-th crack length to beam depth ratio, $1_{\mathrm{F} 0}=$ first full FPZ length at zero initial crack, and a/D = crack length-tobeam depth ratio, respectively. Eq. (4) indicates that the relative full FPZ length decreases linearly with increasing crack length to beam depth ratio.

\subsection{Shape and progress of FPZ}

Several researchers investigated on the width and shape of the fracture process zone in concrete[20-23]. Vesely et al.[20] studied an 
estimation of the size and shape of the FPZ by employing a combination of various approaches from different field of theory of fracture mechanics and plasticity. Figure 5 shows the evolution of damage zone extent at various stages of loading for three point bending[20]. Here, the Stages 'A' to ' $F$ ' represent the corresponding load points in the load-deflection curve in three point bending beam and $\alpha$ represents relative effective crack length. The stage ' $B$ ' represent the damage region at the point of maximum load in three point beam and the stage ' $F$ ' is just before the end of failure. It can be seen from Figure 5 that the shape of the damage(fracture) zone becomes a kind of ellipse as the load proceeds. Figure 5 also indicates that the width of fracture zone becomes narrower as the fracture proceeds to the end of the beam.

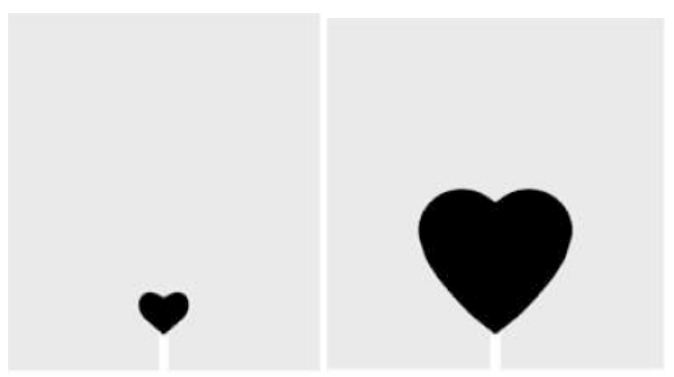

(a) Stage A, $\alpha=0.15$

(b) Stage B, $\alpha=0.35$

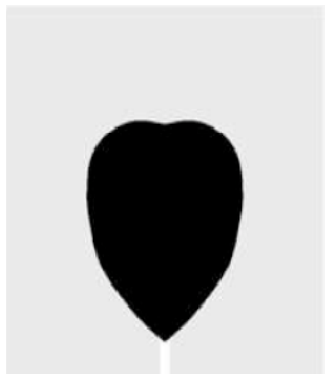

(c) Stage C, $\alpha=0.53$

(d) Stage D, $\alpha=0.70$
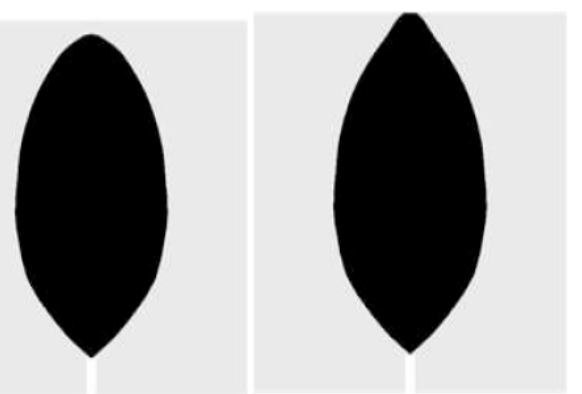

(e) Stage E, $\alpha=0.87$

(f) Stage F, $\alpha=0.97$

Figure 5: Extent of plastic (damage) zones in the stages of fracture process[20].
Trunk and Wittmann [22] assumed that the boundary of FPZ normal to the crack plane increases as crack length increases. However, in view of reduced FPZ length with increasing crack length as discussed in the previous section, it is questionable that the extent of FPZ width increases with increasing crack length.

On the contrary, Vesely et al.[20] showed that the width of fracture(damage) zone increases initially and then decreases with further progress of cracking(loading) as can be seen in Figure 5. It was also reported that the width of tensile iso-stress lines in front of a crack becomes narrower as the ligament length decreases[2].

\subsection{Modeling of formation and progress of FPZ}

In this study, the formation and progress of FPZ has been modeled based on the observation of fracture analysis. The close observation of Figure 1 and Figure 2 describes the sequence of formation and development of FPZ as follows. Firstly, the tensile stress at crack tip reaches the tensile strength at a certain loading. With a further increase of loading, microcracks occur in front of crack tip and the cohesive stresses in front of crack decrease. The cohesive stress at crack tip will vanish with further increase of deformation and the first fully-developed FPZ will be formed at this time. Here the length and width of the first fully-developed FPZ will be defined as $l_{F 1}$ and $w_{F 1}$, respectively. With further increase of deformation after this stage, a certain length of new real crack, $\Delta a$, is produced and another full FPZ is created with the length $l_{F 2}$ and width $w_{F 2}$. As discussed in the previous section(Section 3.1), the length of the fully-developed FPZ may vary from $l_{F 1}$ to $l_{F 2}$ depending upon the ligament size and geometry.

Figure 6 shows the movement and change of fully-developed FPZ length according to fracture progress to the end of three point bend specimen[2]. This figure was newly drawn by employing the results of Petersson's work[2] on FPZ length which was discussed in Section 3.1. Figure 6 explains again the reduction of 
FPZ length as fracture progresses to the end of specimen. Therefore, it may be reasonable to assume here that the width of FPZ may also be reduced as the fracture progresses to the end, which is supported by the results of Vesely et al. as shown in Figure 5. The reduction of the width of FPZ may be due to the steep stress gradient and confining effect as the ligament length decreases.

Therefore, it is modeled here that the length and width of FPZ decrease as shown in Figure 6 as follows, unless the ligament length is very long enough not to have any effect on the full development of FPZ.

$$
\begin{aligned}
l_{F i} & =c(a / D) l_{F 0} \\
w_{F i} & =c(a / D) w_{F 0}
\end{aligned}
$$

where $c=c(a / D)$ is a certain reduction constant which is dependent on ligament size and loading condition ( generally $\mathrm{c}=\leq 1$ ). For the case of beam depth of $200 \mathrm{~mm}$ as discussed in the previous Section 3.1, the reduction factor ' $c$ ' was found to be about $c=[1-0.785(\mathrm{a} / \mathrm{D})]$ as the crack approaches to the ligament end, which can be clearly seen from Figure 4 and Eq.(4). The reduction factor ' $c$ ' is currently a function of $a / D$ which gives good results for this case, but other factors may also affect this value like member size. Therefore, further continuous study will be executed accordingly.

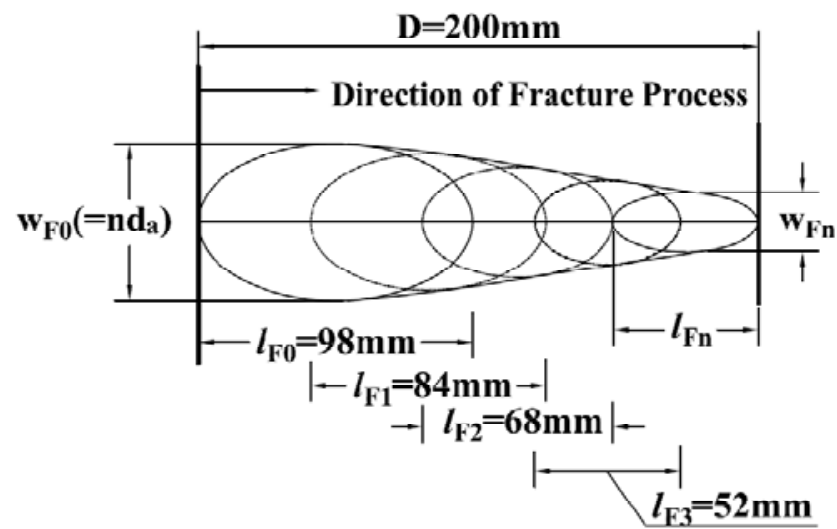

Figure 6: Movement and change of fracture process zone according to fracture progress to the end of specimen in three point bending $(D=200 \mathrm{~mm})$.

Moreover, the shape of fracture process zone is more like an ellipse because, in the beginning, the stresses diffuse out from the crack tip and tensile iso-stress line looks like long ellipse. This was confirmed from the analysis of Vesely et al.[20], in which the damage zone in front of crack becomes an ellipse. Therefore, elliptical shape of FPZ moves to the end of ligament as fracture progresses as shown in Figure 6.

\section{FRACTURE VOLUME AND FRACTURE ENERGY OF CONCRETE}

\subsection{Volume of fracture process zone}

One may now calculate the fractured volume from Figure 6. If this fractured volume is known, it is possible to calculate the fracture energy per unit volume(or per unit area) by using the work of fracture which was experimentally measured from the specimen. The total volume of the fractured zone may be calculated from Figure 6 and may be written as follows.

$$
\begin{aligned}
V_{F}= & {\left[\frac{\pi}{2} \frac{l_{F 1}}{2} \frac{w_{F 1}}{2}+\frac{1}{2}\left(w_{F 1}+w_{F n}\right)\left(\mathrm{D}-\mathrm{a}_{0}-\frac{l_{F 1}}{2}-\frac{l_{F n}}{2}\right)+\right.} \\
& \left.\frac{\pi}{2} \frac{l_{F n}}{2} \frac{w_{F n}}{2}\right] \cdot t
\end{aligned}
$$

where ' $t$ ' is the thickness of specimen, $l_{F 1}$ and $w_{F 1}=$ the length and width of the first fullydeveloped FPZ, $l_{F n}, w_{F n}=$ the length and width of last FPZ near the ligament end, respectively. Now, there is one thing to clarify to use Eq. (7). Namely, how can one determine the width of FPZ such as $w_{F 1}, w_{F n}$ ? As discussed in Eq.(5) and Eq.(6), the length and width of full FPZ reduces from the first-developed full FPZ with the increase of crack length(or with decrease of ligament length). This reduction factor was found to be $c=[1-0.785(\mathrm{a} / \mathrm{D})]$ for the case of beam depth of $200 \mathrm{~mm}$ [see Figure 4]. However, one still need the value of the width of first-developed full FPZ, $w_{F 1}$, to calculate the total fractured volume based on Eq. (7). This will be discussed in the following Section 4.3.

\subsection{Calculation of fracture volume and fracture energy}

In order to apply the present method described in the previous sections, the fracture volume was calculated for the case of Abdalla and Karihaloo's test data on the three point beam of $\mathrm{D}=200 \mathrm{~mm}[16]$. The initial crack to 
beam depth ratio is $\alpha=a / D=0.05$ which is very close to the case of no initial crack. The measured fracture energy for this case was $G_{f}$ $=104.8 \mathrm{~N} / \mathrm{m}[16]$. Figure 7 shows the envelope (solid line) of FPZ, which has been proceeded from the left side, according to the method described in Figure 6. The length and width of FPZ decrease with the decrease of ligament length as discussed previously from Eqs.(4)-(6) and shown in Figure 7.

The fracture volume was calculated based on Eq. (7) in which the lengths of FPZ, $l_{F 1}$ and $l_{F n}$ were calculated from Figure 3 and Figure 4. The calculated fracture volume $V_{f}$ was found to be $V_{f}=0.1198 w_{F 1} \cdot t\left(\mathrm{~m}^{3}\right)$ where $w_{F 1}$ is the width of the first full FPZ length and ' $t$ ' is the thickness of beam. If the fracture process zone is not influenced and develops fully, it would look like the envelope of dashed line(outside envelope) in Figure 7. In this case, the total volume of FPZ is calculated as $V_{F}=0.1698 w_{F 1}$. $t\left(\mathrm{~m}^{3}\right)$. Therefore, the fracture energy $G_{F}$ for the case of fully-developed FPZ may be calculated as $G_{F}=\left(V_{F} / V_{f}\right) \cdot G_{f}=1.417 G_{f}$ $=148.5 \mathrm{~N} / \mathrm{m}$.

Abdalla and Karihaloo proposed that the size-independent fracture energy for this case is about $G_{F}=144.5 \mathrm{~N} / \mathrm{m}$ [16], which is very close to the value $\left(G_{F}=148.5 \mathrm{~N} / \mathrm{m}\right)$ calculated from the present method for the case of fullydeveloped FPZ.

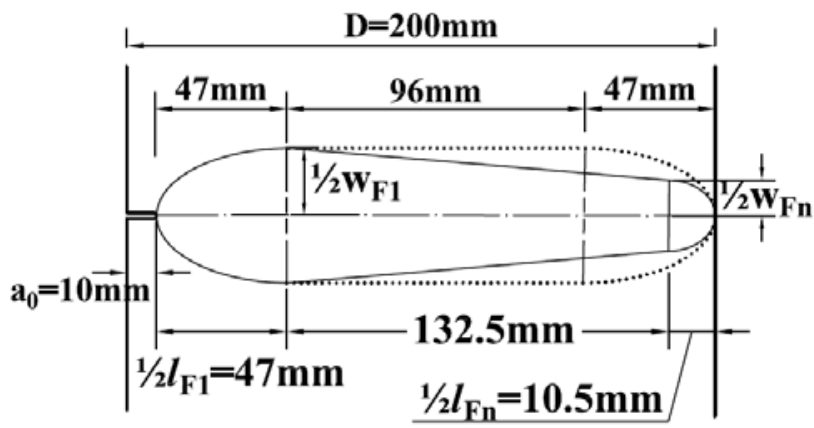

Figure 7:Calculation for the progress envelope of fracture process zone to the end of specimen for Abdalla and Karihaloo's test data on three point beam $(\mathrm{D}=200 \mathrm{~mm})$.

\subsection{Width of fracture process zone}

The width of fracture process zone, $w_{F 1}$, is necessary to calculate the volume of FPZ as shown in the previous section. There are some researches exploring the extent of FPZ in concrete[1, 23, 24]. Bazant and $\mathrm{Oh}[1]$ proposed the FPZ width to be about three times the maximum aggregate size. This was confirmed later by the work of Denarie et al.[23]. Denarie et al. characterized the fracture process zone inside a cracked concrete specimen through optical fiber technology and found that the width of the fracture process zone is about three times the maximum aggregate size[23].

Recently, Muralidhara et al.[24] studied the extent of FPZ using acoustic emission(AE) technique. It was shown that the highlylocalized width of the AE events was found to be about $60 \mathrm{~mm}$ in three point beams (Beam depth $\mathrm{D}=190 \mathrm{~mm}$ ) where the maximum aggregate size was $20 \mathrm{~mm}[24]$. Therefore, it can be said that the width of FPZ may be about three times the maximum aggregate size from this study [24].

The width of fracture process zone mentioned above may be used to calculate the volume of FPZ. However, it is still necessary to clarify whether the width of FPZ varies depending upon the size of members. In another word, one may need to explore whether there exist any size effects in the width of FPZ. For a very large specimen, the FPZ will be developed fully without receiving any effects on sizes and then the width of FPZ can be clarified at the same time for this large specimen. Therefore, it is necessary study further on this subject of the width of FPZ in concrete.

\section{CONCLUSIONS}

Fracture energy of concrete has been a major issue in the fracture mechanics area of concrete structures. It plays a key role in the analysis and evaluation of fracture process in concrete. So far, the fracture energy of concrete has been identified by the energy per unit cracked-area. However, the fracture in concrete proceeds with the fracture process zone in front of crack tip. This fracture process zone(FPZ) has a certain width and therefore it constitutes a certain fractured volume. 
In this study, therefore, the development of fracture process zone was modeled based on the concept of fractured volume. The fractured volume was defined in terms of the length and width of the fracture process zone along the ligament.

It was found that the length of fracture process zone decreases as the crack propagates along the ligament. The reason may be due to the fact that the available space for the FPZ to develop fully becomes smaller as crack propagates and also the ligament must accommodate the stress gradient to maintain equilibrium.

The length of fracture process zone was modeled based on the data of cohesive stress analysis. The continuous change of length and width of fracture process zone was modeled as a crack propagates along the ligament. This change of FPZ length and width may depend on the size of members until they reach the fully-developed limiting values which do not change any more.

Therefore, further study is necessary to clarify the pattern of change of FPZ size along the ligament according to various sizes because the decreasing pattern of FPZ size according to crack-to-depth ratio may be different for different member sizes. This task must be also implemented for the variation of width of FPZ for varying sizes of members. This will enable us to describe reasonably the fracture energy of concrete per unit volume for any sizes of members.

\section{ACKNOWLEDGMENT}

The present study was supported partially by the National Research Foundation of Korea (Project No. NRF-2014R1A1A2058565). The financial support from National Research Foundation of Korea is gratefully acknowledged.

\section{REFERENCES}

[1] Bazant, Z.P., and Oh, B.H. 1983. Crack Band Theory for Fracture of Concrete. Materials and Structures 16: 155-177.

[2] Petersson, P.E. 1981. Crack Growth and Development of Fracture Zones in Plain
Concrete and Similar Materials. Report TVBM 1066, Lund, Sweden, 174pp.

[3] Mindess, S.1984. The Effect of Specimen Size on the Fracture Energy of Concrete, Cement and Concrete Research14(3): 431-436.

[4] F.H.Wittmann, F.H., Mihashi, H. and Nomura, N.1990. Size Effect on Fracture Energy of Concrete. Engineering Fracture Mechanics 35(1-3): 107-115.

[5] Bazant, Z.P., and.Kazemi,M.T. 1991.Size Dependence of Concrete Fracture Energy determined by RILEM Work-of-Fracture Method. International Journal of fracture 51:121-138.

[6] Guo, X.H., and Gilbert, R.I. 2000. The Effect of Specimen Size on the Fracture Energy and Softening Function of Concrete. Materials and Structures 33:309-316.

[7] Kwon, S.H., Zhao, Z. and Shah, S.P. 2008. Effect of Specimen Size on Fracture Energy and Softening Curve of Concrete: Part II. Inverse Analysis and Softening Curve. Cement and Concrete Research 38 : 1061-1069.

[8] Guinea, G.V., Planas, J. and Elices, M. 1992. Measurement of the Fracture Energy using Three Point bend Tests: Part 1-Influence of Experimental Procedures. Materials and Structures 25: 212-218.

[9] Planas, J., Elices, M. and Guinea, G.V. 1992. Measurement of the Fracture Energy using Three Point bend Tests: Part 2-Influence of Bulk Energy Dissipation. Materials and Structures 25: 305-312.

[10] Elices, M., Guinea, G.V. and Planas, J. 1992. Measurement of the Fracture Energy using Three Point bend Tests: Part 3-Influence of cutting the P- $\delta$ Tail. Materials and Structures 25: 327-334.

[11] Hu, X. and Wittmann, F.H. 2000. Size Effect on Toughness induced by Crack close to Free Surface. Engineering Fracture Mechanics65:209-221.

[12] Duan, K., Hu, X. and Wittmann, F.H. 2003. Boundary Effect on Concrete Fracture and Non-Constant Fracture Energy Distribution. Engineering 
Fracture Mechanics70:2257-2268.

[13] RILEM TC-50 (Draft Recommendation). 1985. Determination of the Fracture Energyof Mortar and Concrete by means of Three Point Bend Tests on Notched Beams. Materials and Structures 18 (106): 285-290.

[14] RILEM Draft Recommendation. 1990. Size-Effect Method for determining Fracture Energy and Process Zone Size of Concrete. Materials and Structures 23:461-465.

[15] Bazant, Z.P., and Kazemi, M.T. 1990. Determination of Fracture Energy, Process Zone Length and Brittleness Number from Size Effect with Application to Rock and Concrete. International Journal of fracture 44:111131.

[16] Abdalla, H.M., and Karihaloo, B.L. 2003. Determination of Size-Independent Specific Fracture Energy of Concrete from Three-Point Bend and Wedge Splitting Tests. Magazine of Concrete Research 55(2): 133-141.

[17] Karihaloo, B.L., Abdalla, H.M., and Imjai, T. 2003. A Simple Method for determining the True Specific Fracture Energy of Concrete. Magazine of Concrete Research 55(5): 471-481.

[18] Cifuentes, H., Alcalde, M. and Medina, F. 2013. Comparison of the SizeIndependent Fracture Energy of Concrete obtained by Two Test Methods. In van Mier et al.(Eds). Proceedings of 8thInternational Conference on Fracture Mechanics of Concrete and ConcreteStructures (FraMCoS-8); 1-8.

[19] Gopalaratnam, V.S., and Ye, B.S. 1991. Numerical Characterization of the Nonlinear Fracture Process in Concrete. Engineering Fracture Mechanics40(4): 991-1006.

[20] Vesely, L., Frantik, P. 2010. Reconstruction of a Fracture Process Zone during Tensile Failure of Quasi-Brittle Materials. Applied and Computuiational Mechanics 4; 237-250.

[21] Saucedo, L., Yu, R.C. and Ruiz, G. 2012. Fully-Developed FPZ Length in Quasi-
Brittle Materials.International Journal of Fracture 178: 97-112.

[22] Trunk, B., and Wittmann, F.H. 2001. Influence of Size on Fracture Energy of Concrete. Materials and Structures 34: 260-265.

[23] Denarie, E., Saouma, V.E., Iocco, A. and Varelas, D. 2001. Concreter Fracture Process Zone Characterization with Fiber Optics. Journal of Engineering Mechanics 127(5): 494-502.

[24] Muralidhara, S., Raghu Prasad, B.K., Eskandari, H. and Karihaloo, B.L. 2010. Fracture Process Zone Size and True Fracture Energy of Concrete using Acoustic Emission, Construction and Building Materials 24; 479-486. 